and wet bulbs by Glaisher's tables had been compared with those given by a new form of hygrometer designed by Prof. Chrystal of Edinburgh University. As regards Mr. Aitken's screen, in some a fan was introduced in order to secure a proper and uniform circulation of air for the thermometers in all weathers; others were simply sunshades; one consisted of two thermometers, one of which was partially blackened; and another of a thermometer having its bulb inclosed in a tightfitting silver sheath, highly polished. The construction of Prof. Chrystal's hygrometer was explained and a brief account given of the results either already arrived at or suggested during the investigation, and it was intimated the inquiry was to be resumed at the Ben Nevis Observatory during August and September. At this Observatory, the climate of which offers unique facilities for the prosecution of such inquiries, an instrument of novel construction would be added, which had been designed by Prof. Tait for hygrometric research. Prof. Ewing, of Dundee, then described the arrangements which had been made for commencing the proposed earthquake observations on Ben Nevis this summer. The investigation was to include earthquakes proper; earth movements of so very delicate a kind as to be totally indistinguishable without some form of instrumental assistance, which are conveniently called earth tremors; and there were what might be named changes of the vertical, or those tiltings which the earth's surface seemed to be constantly undergoing. The different seismometers to be employed at the Observatory were then described, and in illustration some of the more striking peculiarities of the earthquakes of Japan were referred to.

\section{PROF. KIESSLING'S INVESTIGATIONS INTO THE ORIGIN OF THE LATE SUNSET GLOWS ${ }^{1}$}

THE interesting and important experimental demonstrations lately made by Prof. Kiessling of Hamburg to illustrate the artificial formation of all manner of sunset effects are probably well known to meteorologists in general. The September number of Das Wetter contains a valuable series of comparisons tending to show that the conditions under which artificial glows were produced have actually existed whenever the remarkable sunset effects have made themselves prominent. The following abstract may prove of interest to those who do not receive the paper itself.

With regard to the "after-glow," or re-illumination, he suggests two explanations as possible:- $-(a)$ Simple reflection of the refracted rays essential to the formation of the ordinary sunset-glow (the first glow); or (b) direct diffraction by a second homogeneous haze at much greater elevation. He considers, however, that the calculated heights of the latter place it out of the question. To the former there are only two important objections, the chief one being the slight polarisation, so far as the very scanty records indicate. The observations are, however, exceedingly deficient. Still, Prof. Kiessling has to allow that they do not tell in favour of the proposed explanation. The other difficulty is the position of the glow. It presupposes a mirror-like surface, parallel to the earth, with the intermediate space unusually transparent, conditions at first sight very improbable at the altitudes under consideration. But Prof. Kiessling's own experiments, detailed at the end of his paper on "Die Dämmerungserscheinungen im Jahre 1883 ," have shown the possibility. In these he obtained results most remarkably similar to those requiring explanation, and by methods reproducing in a striking manner the conditions considered actually to exist in the atmosphere.

A warm, moist stratum of air being produced in contact with a cold stratum the resulting haze along the contact surface formed the site of diffraction phenomena, approaching those actually observed in ordinary brilliant sunsets according to the fineness of the haze particles, and also reflections reproducing the "after-glow."

The almost constant saturation of the cold upper strata in winter is indicated by observations at high-level stations and the persistent upper haze. Let a warm [cyclonic] current come beneath such a layer, then the fine haze at the surface of contact will have beneath it the peculiarly transparent atmosphere common to such conditions and requisite for the transmission of the result-

I Ueber die Entstehung des zweiten Purpurlichtes und die Abhängigkeit ter Dämmerungsfarben von Druck, Temperatur, und Feuchtigkeit der luft Das Wetter, vol. ii. No. 9. p. 16r. ing diffraction (and reflection) phenomena. This should be found to exist in all brilliant sunsets, Prof. Kiessling stating the following law :-An intense purple glow, zisible over a considerable area, may occur when, in close proximity beneath a lofty and highly-attenuated haze, there is formed an extensive stratum of air at considerably higher temperature.

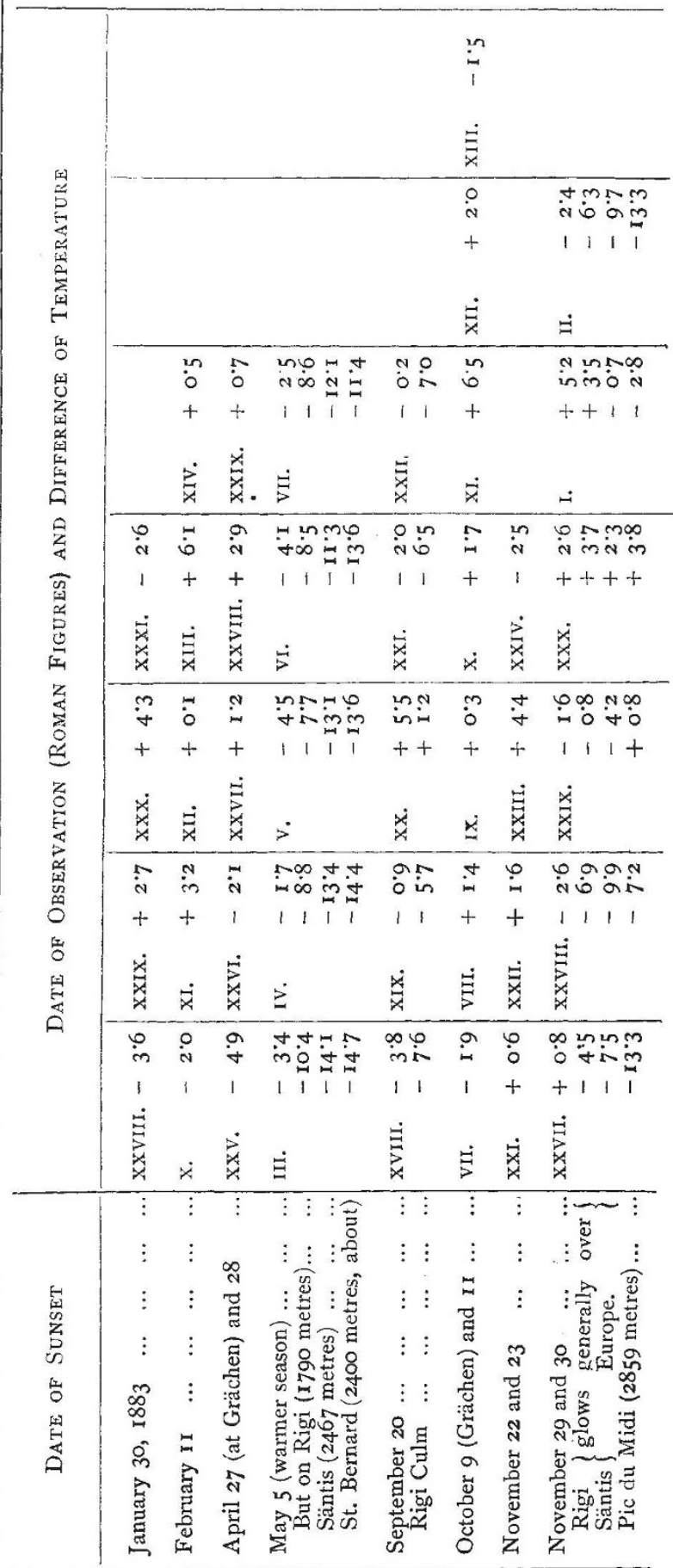

Although we cannot ever expect direct observations of temperature at the common surface producing the sunset glows, yet, as Prof. Kiessling shows, if we can prove that the warm undercurrent always accompanies sunset glows, the proof is practically complete. Such indications may be expected during the colder seasons in the form of abnormal vertical distribution of tempera- 
ture, an increase instead of decrease at higher stations. $\mathrm{He}$ brings forward a long array of figures supporting this conclusion, especially for sunrise effects in 1883 , as seen from Säntis $(2467$ metres), in North-East Switzerland, in the bend of the Rhine. Stations to the east-Munich ( 528 metres) and Hohen Peissenberg ( 994 metres) are taken for observations on temperature and relative humidity. The last place is about 35 miles south-west of Munich ; both may be considered as beneath the sky region producing glows at Säntis. As difference of temperalure is the most decisive comparison, his tables are here reduced to a series showing the difference of Hohen Peissenberg returns from Munich, in degrees Centigrade. In some cases one or two other returns are also added, reduced in like manner. Normally, allowing for difference of height, Hohen Peissenberg should register $2^{\circ} .5$ below Munich.

The final set of observations refer to some of the earlier afterglows. The greater anomaly with greater elevation (increases of $5^{\circ} \cdot 2,10^{\circ} \cdot 6,12^{\circ} \cdot 2$; and $17^{\circ} \cdot \mathrm{I}$ respectively in the figures given) is very suggestive. The reason of the non-agreement in May has already been stated.

Except the last, these observations refer to ordinary sunrise effects, but the only difference between them and the recent glows is considered to be that the latter occur by reflection at a higher level and in a more finely attenuated haze, thus giving the richer effects. The presence of such a haze with the glows was a matter of very common observation.

The question, of course, requires further consideration, especially with respect to observations of the recent glows. Besides this connection with a warm stratum of air, Prof. Kiessling finds another, almost as general, with barometric maxima, as was noticed with the similar phenomena in $\mathrm{r} 88 \mathrm{r}$.

Referring, in his concluding paragraph, to the connection of the glows with the Krakatoa eruption, Prof. Kiessling writes that the thousand or so records of their geographical distribution, now in his hands, "show a perfectly continuous spread of the anomalous glows, and of the diffraction phenomena of Bishop's Ring dating from August 26, I $88_{3}$, and spreading from the Straits of Sunda as a centre over the tropical and temperate zones."

J. EdMund Ciark

\section{A CENTURY OF SCIENCE IN BENGAL}

$\mathrm{I} \mathrm{T}$ was a happy idea of the Council of the Asiatic Society of Bengal to commemorate the completion of a century of the Society's existence by publishing a review of the progress made and the services rendered to knowledge by the institution. ${ }^{1}$ The idea of a learned society composed of Europeans in India studying the country and communicating to each other at periodical meetings the results of their researches, arose first in the fertile brain of Sir William Jones, who was inclge in the Supreme Court at Fort William, and who delivered, on January 15,1784 , to about thirty members of the European community of Calcutta, a "Discourse on the Institution of a Society for Inquiring into the History, Civil and Natural, the Antiquities, Arts, Sciences, and Literature of Asia." As a result of this discourse, the "Asiatick Socicty," the parent of all such societies, was founded. Its motto, which is taken from Sir William Jones's discourse here referred to, is this: "The bounds of its investigations will be the geographical limits of Asia, and within these limits its inquiries will be extended to whatever is performed by man or produced by nature." After many vicissitudes it has just completed its hundredth year, and the record of its work forms the large volume just mentioned. This is divided into three parts : first, a history of the Society, by Dr. Mitra ; its work in archæology, history, and literature, hy Dr. Hœrnle ; and the work in natural science, by Baboo P. N. Bose. The change which has come over the face of India in the course of a century could hardly be better marked than by the fact that two out of the three parts into which the volume is divided-one of these being on natural science-are written by native gentlemen. In the history of the Society we notice that in 1808 a resolution was proposed by Dr. Hare and seconded by Dr. Leyden (frequently referred to in Lockhart's "Life of Scott"), "that a Committee be appointed for the purpose of physical investigations, the collection of facts, specimens, and correspondence with individuals whose situations in this country may be favourable for such discussions and investigations." It was then agreed to provide two committees-

1 "Centenary Review of the Asiatic Society of Bengal, I 784 to $188_{3}$." Published by the Society, Calcutta. Thacker, Spink, and Co., ${ }_{1885}$. one for science, the other for literature; twenty years later, in 1828 , a committee was appointed "to promote geological researches, working under the rules then in force for the Physical Committee," and at the same time the published Transaitions of the Society were divided into two parts, one devoted to physical, the other to literary subjects. Nearly twenty years Jater the whole of the work of the Socicty was delegated to six committees, one having charge of zoology and natural history, another of geology and mineralogy, and a third of meteorology and physics. The establishment of a museum dich not occur to the founder, but curiosities were constantly coming in from members, and in 1796 it was proposed to give these a suitable house. In I8I4 Dr. Wallich proposed the formation of a museum, and offered duplicates from his own collections, as well as his services in arranging it, and a museum was accordingly started. The story of the growth of the various sections of the Natural History Museum is told by Dr. Mitra. On the whole it is one of great progress, although financial difficulties beset the museum at first. But as soon as the Society became able to pay for scientific curators all went well. In 1865 the Society's zoological, geological, and archæ?logical collections were marle over to the Government of India for the public museum in Calcutta. A writer in the Calcutta Review, speaking of the Society's exertions for the establishment of the national museum, said: " $\mathrm{Had}$ it done nothing else to promote science during the last ten years, it would have entitled itself to the gratitude of posterity for the vigour with which it has prosecuted to success a project fraught with so much public usefulness." The earlier volumes of the Socicty's Transactions, published unfer the title " Asiatick Researches," created a sensation in the literary and scientific world in Europe. A French translation was speedily published, with notes on the scientific portions by no lesser hands than Cuvier, Lamarck, Delambre, and Olivier. Of the work of the Society in peserving Sanskrit MSS., in translating and publishing various works from the native languages, and other valuable services to literature, Dr. Mitra speaks at length. Amongst the publications, apart from the papers, we notice many of scientific interest, such as catalogues of various sections of the museum, of the mammals and birds of Burmah, of Indian lepidoptera, besides translations of numerous works of Hindoo science. In summing up at the conclusion of his historical sketch the benefits conferred on India and the world by the Society during its hundred years of existence, Dr. Mitra sums up its scientific work (apart from papers, and published volumes above referred to) thus: "It got up an archæological and ethnological m:seum of considerable extent, a geological museum rich in meteorites and Indian fossils, and a zoological museum all but complete as re gards the avifauna of India."

The long review of the work of the Society in natural science is, as already mentioned, written by Baboo Bose. His method is to take the various branches of science in succession, such as mathematical and physical science, geology, zoology, botany, geography, ethnology, and chemistry, and to describe under sub-heads the paper on these subjects contributed to the Transactions of the Society, together with a brief biographical sketch of the more cclebrated or prolific authors. At the end we get a classified index of all the scientific papers, an alphabetical list according to the author's names being given at the conclusion of the first part. Amongst the latter we notice many whose names are familiar as contributors to NATURE. In the early years of the Society, and down to 1828 , the scientific contributions to the Society's Proceedings were almost wholly connected with some branch of pure or mixed mathematics, for most of the men who went out to India, especially in the scientific branches of the military service, had been well grounded in this subject. The section on the investigations into the mathematical science of the Hindoos is of great interest. Sir William Jones put before the Society from the outset the object of studying these sciences, and he set the example himself, but the initial difficulty was to find any native capable of assisting him. Baboo Bose records that, although ample stipends were offered by Sir William Jones to any Hindoo astronomer who could name in Sanskrit all the constellations which he would point out, and to any Hindoo physician who could bring him all the plants mentioned in Sanskrit books, he was assured by the Brahmans whom he had commissioned to search for such instructors, that no Pundit in Bengal even pretended to possess the knowledge he required. Geology and mineralogy flourished in the Society from the commencement, while zoology was at first unduly depressed and discouraged owing 